\title{
A POLÍTICA DE COTAS NOS SEGMENTOS DA EDUCAÇÃO BÁSICA NO COLÉGIO PEDRO II
}

\author{
Gabriela dos Santos Coutinho ${ }^{1}$ \\ Dyego de Oliveira Arruda ${ }^{2}$ \\ Talita de Oliveira ${ }^{3}$
}

\begin{abstract}
RESUMO: Este artigo objetiva analisar o modo como o Colégio Pedro II, no Rio de Janeiro, implementa a política de cotas nos processos de admissão de alunos para os diferentes segmentos da educação básica. Em suma, indagamos se a política de cotas se traduziu na presença de um maior quantitativo de pessoas negras no corpo discente da instituição. A partir do estudo dos editais de seleção discente e da análise do perfil racial dos alunos, constatamos que, a despeito de o Colégio Pedro II aplicar a política de cotas raciais em seus processos seletivos, a instituição o faz apenas para o Ensino Médio (conforme prevê, em sentido estrito, a Lei n. 12.711/2012), não contemplando os demais segmentos da educação básica e, portanto, pouco modificando o perfil racial do corpo discente nos últimos anos.

Palavras-chave: Educação básica. Ação Afirmativa. Cotas raciais. Colégio Pedro II.
\end{abstract}

\section{THE POLICY OF QUOTAS IN THE BASIC EDUCATION SEGMENTS AT COLÉGIO PEDRO II}

\begin{abstract}
This article aims to analyze how Colégio Pedro II, in Rio de Janeiro, Brazil, implements the policy of quotas in student admission processes for different segments of basic education. In short, we investigate whether the policy of quotas resulted in the presence of a greater number of black people in the institution's student body. Based on the study of the civil service examination announcements for the selection of students and on the analysis of the student's racial profile, we found out that, even though Colégio Pedro II applies the policy of racial quotas in its announcements, the institution does so only for secondary education (as provided by Law n. 12,711/2012, in the strict sense). That is to say the institution is not covering the other segments of basic education and, therefore, there is little change in the racial profile of the student body in recent years.
\end{abstract}

Keywords: Basic education. Affirmative Action. Racial quotas. Colégio Pedro II.

O artigo é resultado de pesquisa desenvolvida no Programa de Pós-graduação em Relações Étnico-raciais (PPRER), do Centro Federal de Educação Tecnológica Celso Suckow da Fonseca (Cefet-RJ), e está vinculado ao projeto "Mídia, narrativa e identidade: raça e racismo numa perspectiva sócio-discursiva".

1.Colégio Pedro II - Departamento de Anos Iniciais do Ensino Fundamental - Campus Realengo I - Rio de Janeiro (RJ), Brasil. E-mail: gabriela.gsc@gmail.com

2.Centro Federal de Educação Tecnológica Celso Suckow da Fonseca - Diretoria de Pesquisa e Pós-graduação - Programa de Pós-graduação em Relações Étnico-raciais - Rio de Janeiro (RJ), Brasil. E-mail: dyego.arruda@cefet-rj.br

3.Centro Federal de Educação Tecnológica Celso Suckow da Fonseca - Diretoria de Pesquisa e Pós-graduação - Programa de

Pós-graduação em Relações Étnico-raciais - Rio de Janeiro (RJ), Brasil. E-mail: talita.oliveira@cefet-rj.br

Editor de Seção: Salomão Barros Ximenes

Editores convidados: Nilma Lino Gomes, José Eustáquio Brito e Paulo Vinicius Baptista da Silva 


\section{LA POLÍTICA DE CUOTAS EN LOS SEGMENTOS DE LA EDUCACIÓN BÁSICA EN EL COLEGIO PEDRO II}

RESUMEN: Este artículo tiene como objetivo analizar cómo el Colegio Pedro II, en Río de Janeiro, Brasil, implementa la política de cuotas en los procesos de admisión de estudiantes para diferentes segmentos de la educación básica. En resumen, preguntamos si la política de cuotas ha resultado en la presencia de una mayor cantidad de negros en el alumnado de la institución. Con base en el estudio de los avisos de selección de estudiantes y en el análisis del perfil racial de los estudiantes, encontramos que, aunque el Colegio Pedro II aplique de la política de cuotas raciales en sus procesos de selección, lo hace solamente en la educación secundaria (de acuerdo con la Ley n. 12.711, 2012, en sentido estricto), descuidando de los demás segmentos de la educación básica y, por lo tanto, modificando poco el perfil racial del alumnado en los últimos años.

Palabras-clave: Educación Básica. Acción Afirmativa. Cuotas raciales. Colegio Pedro II.

\section{Introdução}

A

naturalização da lógica do racismo no contexto social brasileiro fez com que as pessoas negras ficassem historicamente alijadas de determinados espaços de poder e de agência, monopolizados quase que exclusivamente por pessoas brancas (MUNANGA, 2001). Quando se analisa a realidade do ambiente escolar, percebe-se que os corpos negros não são presença constante e naturalizada nesses espaços, sobretudo quando se considera o contexto de estabelecimentos de ensino tomados como referência técnica e pedagógica - caso do Colégio Pedro II (CPII), uma tradicional instituição federal de ensino localizada no estado do Rio de Janeiro.

Segundo a Pesquisa Nacional por Amostra de Domicílios Contínua (PNAD-C) de 2019, a taxa de jovens entre 15 e 17 anos que frequentavam o Ensino Médio no período em análise é de 79,6\% para pessoas brancas e $66,7 \%$ para pessoas negras (pretas ou pardas) (IBGE, 2020). Ainda de acordo com a mesma fonte, dos mais de 10 milhões de jovens entre 14 e 29 anos que não completaram alguma das etapas da educação básica no ano de 2019, constata-se que 27,3\% do total eram pessoas brancas, ao passo que o percentual de pessoas negras que abandonaram a escola ou mesmo jamais a frequentaram é de impressionantes $71,7 \%$ do total em análise.

Diante da realidade em que as pessoas negras são sistematicamente excluídas dos espaços escolares, são fundamentais Políticas de Ação Afirmativa que considerem o marcador racial e, portanto, possibilitem que os indivíduos negros façam valer o seu direito à educação, que idealmente deve apresentar um caráter inclusivo e democrático, independentemente do pertencimento racial dos sujeitos (MOEHLECKE, 2002; FERES JÚNIOR et al., 2018).

Tomando as políticas de gratuidade e obrigatoriedade da educação básica como direito dos cidadãos e dever do Estado, considera-se que todos os indivíduos têm - ou deveriam ter - acesso às escolas públicas municipais, estaduais ou federais, conforme determinações legais que constam no Art. 208 da Constituição Federal (BRASIL, 1988). Todavia, como mostram os índices citados nos primeiros parágrafos deste texto, percebe-se que a realidade é outra. $\mathrm{O}$ insucesso escolar do grupo que sofre historicamente com as desigualdades racial e social mantém vínculos explicativos com o racismo peculiar vivido no Brasil, que segrega e cerceia a permanência dos indivíduos negros na escola. 
O ingresso à maior parte das escolas públicas consiste em inscrição e matrícula, de acordo com a disponibilidade de vagas nas unidades de ensino. O cenário começa a mudar quando falamos em escolas federais, em Colégios de Aplicação vinculados a universidades e a institutos de educação, ou mesmo quando tratamos de escolas públicas que oferecem Ensino Fundamental integral e/ou Ensino Médio-Técnico integrado. Essas escolas apresentam uma demanda de potenciais interessados muito grande e, por isso, faz-se necessária alguma estratégia de seleção de alunos, seja por meio de sorteio, seja por prova classificatória.

O CPII se enquadra nessa última situação, sendo reconhecido no cenário educacional como uma escola de excelência, título chancelado pelos índices alcançados em exames nacionais e pela procura crescente por vagas disponibilizadas para o ingresso de alunos, em sorteios e demais processos seletivos. No Índice de Desenvolvimento da Educação Básica (Ideb) relativo ao ano de 2019, por exemplo, o CPII obteve nota média de 7,34 nos anos iniciais do Ensino Fundamental e de 6,40 nos anos finais dessa etapa de ensino valores que são significativamente superiores em relação à nota média de outros estabelecimentos, públicos ou privados, que oferecem o mesmo segmento de ensino no país e no Estado do Rio de Janeiro (COLÉGIO PEDRO II, 2020a).

$\mathrm{Na}$ construção do discurso da excelência - e das ideias que a ela se associam, como prestígio e tradição -, cabe uma análise crítica sobre quais alicerces estabeleceram o CPII como referência de escola de qualidade no imaginário brasileiro. Destacamos, olhando para o passado da instituição, o contexto de surgimento da escola no período imperial escravocrata, com o objetivo de formação das elites locais (COLÉGIO PEDRO II, 2021a; CUNHA JÚNIOR, 2008).

Contemporaneamente, percebe-se que, a reboque do imaginário de excelência que cerca o CPII, a instituição ainda se mostra significativamente elitizada, numa dinâmica em que são minoria os estudantes negros que estudam na escola, conforme será melhor descrito adiante. Desse modo, entendemos ser crucial o conjunto de Políticas de Ações Afirmativas com recorte racial que possibilitem que a instituição se torne mais diversa e inclusiva.

Vale frisar que as Políticas de Ações Afirmativas no Brasil foram institucionalizadas principalmente a partir do Estatuto da Igualdade Racial (Lei n. 12.288, de 20 de julho de 2010), que preconizou, em seu Art. 56 , o estabelecimento de "[...] iniciativas que incrementem o acesso e a permanência das pessoas negras na educação fundamental, média, técnica e superior” (BRASIL, 2010, s. p).

De todo modo, a consolidação das políticas de cotas em nível federal só ocorreu em 2012 com a promulgação da Lei n. 12.711 (popularmente conhecida como "Lei de Cotas"), que estabeleceu a reserva de $50 \%$ das vagas em universidades federais e instituições federais de ensino técnico de nível médio para estudantes que tenham cursado integralmente em escolas públicas o Ensino Médio (vagas para graduação) ou o Ensino Fundamental (vagas para Ensino Médio-Técnico) (BRASIL, 2012a). Dentro das cotas por origem escolar, foram determinadas as subcotas para estudantes autodeclarados pretos, pardos e indígenas, para pessoas com deficiência e para estudantes oriundos de famílias com renda igual ou inferior a 1,5 saláriomínimo per capita.

Portanto, o sistema de cotas que a Lei n. 12.711 instituiu é, em primeiro lugar, para estudantes egressos de escolas públicas. Se o indivíduo não for originário de escola pública, ele não pode ser beneficiário do sistema de cotas estabelecido pela legislação em análise, mesmo sendo preto, pardo ou indígena, ainda que sua família viva em condições precárias em termos econômicos (SANTOS, 2021). O cálculo relativo ao quantitativo de vagas a serem reservadas por critério racial e para pessoas com deficiência tem como base inicial o primeiro recorte realizado por critério de origem escolar e deve seguir a proporção respectiva de pretos, pardos, indígenas e pessoas com deficiência da Unidade da Federação onde está instalada a instituição, de acordo com o último censo do Instituto Brasileiro de Geografia e Estatística - IBGE (BRASIL, 2012a). 
Todavia, é importante observar que essa legislação alcança os níveis superior, médio e técnico, no âmbito das universidades federais e dos Institutos Federais de Educação, Ciência e Tecnologia (IF), mas é omissa quanto à educação básica ofertada pelos Colégios de Aplicação instituídos nas universidades federais (MACHADO et al., 2020) e quanto ao CPII, autarquia federal equiparada aos IF por meio da Lei n. 12.677, de 25 de junho de 2012 (BRASIL, 2012b).

Desse modo, destacamos que uma lacuna decorrente da Lei n. 12.711/2012 e das demais legislações que instrumentalizaram o Estatuto da Igualdade Racial foi negligenciar a possibilidade da reserva de vagas com recorte racial nos processos seletivos para todos os segmentos e modalidades da educação básica. Assim, indagamos: como o CPII - que oferece turmas da Educação Infantil à Pós-graduação - instrumentaliza a Política de Ação Afirmativa que viabiliza o acesso de pessoas negras aos cursos dos diferentes segmentos da educação básica, a qual abarca desde Educação Infantil até o Ensino Médio? Afinal, a dinâmica utilizada pela instituição para a reserva de vagas favorece a entrada de maior quantitativo de pessoas negras em seu corpo discente?

Em suma, é com base nos supracitados problemas de pesquisa que este artigo irá se estruturar. Galvão (2003; 2009), Cavaliere (2008), Bastos (2017), Dargains (2015), além de Perrut e Scalercio (2019), são alguns dos pesquisadores que se debruçam sobre o contexto do CPII sob a ótica do recorte sociorracial. Entretanto, o presente artigo se desloca dessas pesquisas, pois foca nas políticas de acesso de estudantes negros na educação básica do CPII como um todo, para além da política de cotas para os Ensinos Médio e Técnico, já deliberadas explicitamente pela Lei n. 12.711/2012.

O objetivo desta pesquisa é, portanto, discutir o modo como o CPII implementa a política de cotas nos processos de admissão de alunos para os diferentes segmentos da educação básica, da Educação Infantil ao Ensino Médio, analisando se a reserva de vagas efetivamente culmina na presença de maior quantitativo de estudantes negros na instituição.

Este artigo traz significativas contribuições, na medida em que avança nas discussões sobre a interpretação e a instrumentalização da Lei n. 12.711/2012, especialmente no atual momento, em que esse dispositivo legal está prestes a completar uma década de vigência. Segundo o Art. $7^{\circ}$ da "Lei de Cotas", em 2022 "será promovida a revisão do programa especial para o acesso às instituições de educação superior de estudantes pretos, pardos e indígenas e de pessoas com deficiência, bem como daqueles que tenham cursado integralmente o Ensino Médio em escolas públicas" (BRASIL, 2012a, s. p). Mais do que nunca, portanto, é o momento oportuno para discutirmos como são implementadas as políticas de reserva de vagas, trazendo à baila elementos que permitam que os grupos historicamente excluídos dos processos de escolarização possam acessar o ambiente escolar, sobretudo daquelas instituições consideradas de prestígio e excelência.

\section{A Perspectiva Racial e as Ações Afirmativas na Educação Básica}

Apesar das tensões, dos desafios e dos limites impostos pelo racismo estrutural, os movimentos sociais negros e suas representações dentro das instituições têm avançado ao longo dos anos no debate e na implantação de políticas públicas que visam à equidade racial. Nilma Lino Gomes, nesse sentido, pontua:

Importa-nos compreender a potência desse movimento social [Movimento Negro] e destacar as dimensões mais reveladoras do seu caráter emancipatório, reivindicativo e afirmativo, que o caracterizam como um importante ator político e como educador de pessoas, coletivos e instituições sociais ao longo da história e percorrendo as mais diversas gerações (2017, p. 23). 
Até a década de 1980, a atuação dos movimentos sociais negros, no que se refere ao acesso à educação, tinha um caráter universalista. Entretanto, ao constatarem que as políticas de universalização da educação não atendiam à grande massa da população negra, as reivindicações dessas organizações tomaram outros contornos. Com a reforma constitucional, no final da década de 1980, emerge uma nova concepção de sociedade e, a partir da segunda metade da década de 1990, a perspectiva racial ganha outra centralidade na sociedade brasileira e nas políticas públicas. É nesse contexto que surgem com maior expressividade as demandas por Ações Afirmativas com foco racial, especialmente para a educação superior e para o mercado de trabalho (GOMES, 2017).

Além de apresentar a primeira manifestação constitucional pós-abolição sobre as culturas afrobrasileiras e indígenas, a Carta Magna de 1988 foi um marco na transição democrática e na institucionalização dos direitos humanos no Brasil. Contudo, como balizadora do ordenamento jurídico nacional, não foi explícita sobre políticas educacionais compensatórias ou reparatórias tendo como base o critério de cor/raça. Essas políticas foram construídas no decorrer das décadas seguintes, não apenas por uma vontade política do poder público, mas principalmente como uma consequência da própria pressão oriunda dos debates que se encontravam em andamento na sociedade, capitaneados pelos diversos movimentos sociais negros.

A partir das reivindicações desses movimentos, foi instituída no âmbito do Governo Federal, em 2003, a Secretaria de Políticas de Promoção da Igualdade Racial (Seppir) com a finalidade de combater o racismo, o preconceito racial e a desigualdade racial deles decorrentes, reverter a representação negativa em relação aos negros e negras e promover igualdade de oportunidades. Na primeira década de existência da Seppir, importantes marcos legais para a promoção da igualdade racial foram efetivados, tais como a Lei n. 10.639/03, uma das primeiras legislações baseadas no princípio das Ações Afirmativas; a Política Nacional de Saúde Integral da População Negra (2006); o Estatuto da Igualdade Racial (Lei n. 12.288/2010); e a sanção da Lei n. 12.711/2012 (MACHADO et al., 2020).

Destacamos que o título III da Lei n. 12.288/2010 indica que, para o financiamento das iniciativas de promoção da igualdade racial, deverão ser observadas as Políticas de Ação Afirmativa e outras políticas públicas que tenham como objetivo promover a igualdade de oportunidades e a inclusão social da população negra, especialmente no que tange a "iniciativas que incrementem o acesso e a permanência das pessoas negras na educação fundamental, média, técnica e superior” (BRASIL, 2010, s. p).

Segundo nosso entendimento, tal estatuto apresenta limitações, ao não citar expressamente as políticas de acesso da população negra à Educação Infantil, bem como ao não explicitar a obrigatoriedade das políticas de acesso a todos os segmentos da educação básica - dinâmica que confere à Lei n. 12.288/2010 um caráter de mera recomendação.

É crucial reconhecer que uma das conquistas decorrentes do Estatuto da Igualdade Racial foi a Lei n. 12.711/2012, legislação que estabeleceu a obrigatoriedade da reserva de 50\% das vagas em universidades e instituições federais de Ensino Técnico de nível médio para estudantes egressos de escolas públicas, com subcotas para pretos, pardos e indígenas, para estudantes oriundos de famílias com baixa renda e para pessoas com deficiência.

Não obstante, vale ressaltar que a Lei n. 12.711/2012 também apresenta fragilidades, sobretudo no tocante ao fato de ter escamoteado a primazia do aspecto racial, diluindo-o no aspecto social, uma vez que o critério de cor/raça se encontra atrelado à exigência de que o estudante seja egresso de escola pública. Tal estratégia pode ter se mostrado factível e conciliadora para fazer prosperar a lei federal em 2012. No entanto, agora, passados quase dez anos, convém questionar se a melhor maneira de corrigir as desigualdades raciais no país é diluir o critério racial em um dos critérios sociais, sejam eles por origem escolar, sejam por hipossuficiência econômica. 
Nesse ínterim, Feres Júnior et al. ponderam que "a sobreposição entre negritude e pobreza não necessariamente torna a Ação Afirmativa baseada exclusivamente na classe um mecanismo eficaz de inclusão de grupos étnico-raciais discriminados" (2018, p. 88). A desigualdade de oportunidades sociais advindas do racismo, vivenciadas pelos candidatos pretos e pardos, permanece nas classes médias e altas.

Ao não contemplar grupos raciais que estão em processos de ascensão social ou já passaram por eles e, portanto, não se encaixam mais nos critérios de baixa renda e escola pública, a Lei de Cotas pode estar ignorando um contingente que deveria ser alcançado pelas políticas afirmativas (FERES JÚNIOR et al., 2018, p. 91).

Percebemos que outra fragilidade da Lei n. 12.711/12 é a omissão quanto aos outros segmentos da educação básica, para além do Ensino Técnico e de nível médio. Uma justificativa possível é de que esses segmentos e modalidades negligenciados nas Políticas de Ação Afirmativa já estão contemplados nas políticas de obrigatoriedade e gratuidade da educação básica, oferecidas pelos municípios - Educação Infantil e Ensino Fundamental - e pelos estados - Ensino Médio regular.

Entretanto, é preciso refletir se as conquistas que se expressam pelas legislações mencionadas se traduziram em ganhos reais para a população negra. Se considerarmos, por exemplo, os Colégios de Aplicação, deparamo-nos com uma realidade peculiar que ainda demanda discussões. Observando como é operacionalizada a reserva de vagas de alguns Colégios de Aplicação do estado do Rio de Janeiro, voltados para os diferentes níveis da educação básica, podemos constatar que não há um entendimento único sobre as políticas de cotas raciais.

Seguindo as determinações das Leis Estaduais n. 6.434/2013 e n. 8.121/2018, o Instituto de Aplicação Fernando Rodrigues da Silveira (CAp-Uerj), que oferece turmas do $1^{\circ}$ ano do Ensino Fundamental ao Ensino Médio - apenas na modalidade regular -, selecionou seus alunos para o ano letivo de 2021 por meio de sorteio público e utilizou o critério socioeconômico como primeiro recorte para a reserva de vagas. Aos candidatos comprovadamente carentes, para o $1^{\circ}$ ano do Ensino Fundamental, foram reservadas as seguintes subcotas: $40 \%$ das vagas para negros, ${ }^{1}$ pardos e indígenas e 5\% para pessoas com deficiência (CAP-UERJ, 2021a). Nos certames para o $5^{\circ}$ e $6^{\circ}$ anos do Ensino Fundamental e para o $1^{\circ}$ ano do Ensino Médio, 45\% das vagas são reservadas sob o critério socioeconômico: $20 \%$ se destinaram a estudantes egressos de escola pública, 20\% a estudantes negros, pardos e indígenas e $5 \%$ a pessoas com deficiência (CAP-UERJ, 2021b). Também tiveram direito à reserva de vagas, para todos os anos de escolaridade ofertados, os filhos de servidores da Uerj, sendo $12,5 \%$ para filhos de professores e 12,5\% para filhos de funcionários do quadro técnico. Para esse grupo, a reserva não tem qualquer relação com a renda familiar (CAP-UERJ, 2021a, 2021b).

Assim como o CPII, nos anos letivos anteriores, os candidatos ao Ensino Fundamental I do CApUerj eram admitidos por sorteio público e os candidatos ao Ensino Fundamental II e ao Ensino Médio passavam por processo seletivo constituído por prova de seleção e classificação. O sorteio para todas as etapas no CAp-Uerj também se constituiu como uma excepcionalidade devido ao contexto pandêmico. Contudo, os critérios para reserva de vagas utilizados em 2021 são os mesmos dos anos anteriores.

O Colégio de Aplicação da UFRJ (CAp-UFRJ), que oferece turmas da Educação Infantil ao Ensino Médio - somente na modalidade regular -, também utilizou o sorteio público como método de seleção discente para o ano letivo de 2021 e realizou a reserva de 50\% do total de vagas para a Educação Infantil e para o $1^{\circ}$ ano do Ensino Fundamental, subdividindo-as nos seguintes grupos: 1) critério racial somado ao critério socioeconômico; 2) somente critério racial; 3) somente critério socioeconômico; e 4) pessoa com deficiência. Tomando como exemplo a distribuição de vagas para o Infantil 2, que apresentava dezesseis 
vagas, tem-se que: duas vagas foram destinadas a pretos, pardos e indígenas comprovadamente carentes; três vagas foram para pretos pardos e indígenas; duas vagas foram para crianças comprovadamente carentes; uma vaga foi destinada a pessoa com deficiência; e oito vagas foram para ampla concorrência (CAP-UFRJ, 2020).

Para o Ensino Fundamental II e para o Ensino Médio, a reserva segue o critério inicial de egressos da rede pública (50\%), com subcotas de 50\% para candidatos carentes, além da proporção racial do estado do Rio de Janeiro para pretos, pardos e indígenas (CAP-UFRJ, 2020). Como exemplo, das trinta vagas efetivas oferecidas para o $1^{\circ}$ ano do Ensino Médio nesse certame, quatro foram destinadas para pretos, pardos e indígenas egressos de escola pública e comprovadamente carentes; quatro vagas foram reservadas para pretos, pardos e indígenas egressos de escola pública; quatro vagas foram para candidatos comprovadamente carentes, egressos de escola pública; três vagas foram para candidatos egressos de escola pública; e quinze para ampla concorrência.

Nos editais que regulamentaram a admissão de alunos para os anos letivos de 2019 e 2020, o CApUFRJ utilizou o sorteio público para todos os segmentos, adicionando prova de nivelamento somente ao $1^{\circ}$ ano do Ensino Médio.

Quanto à reserva de vagas no CAp-UFRJ, nota-se um crescente na operacionalização das cotas. Observando os Editais n. 895/2018 e n. 642/2018, da Escola de Educação Infantil (EEI-UFRJ)² e do CApUFRJ, respectivamente, constatamos que a reserva de vagas por critério social e racial ocorreu apenas para o $6^{\circ}$ ano do Ensino Fundamental e para o $1^{\circ}$ ano do Ensino Médio. A partir do Edital n. 378/2019, o CAp-UFRJ começou a operacionalizar o sistema de cotas por critério social e racial também para o $1^{\circ}$ ano do Ensino Fundamental (não foram oferecidas vagas para a Educação Infantil nesse certame). No Edital n. 475/2020, a reserva de vagas por critério social e racial foi aplicada, como vimos anteriormente, desde a Educação Infantil (EEI-UFRJ, 2018; CAP-UFRJ, 2018, 2019, 2020).

Nos editais de admissão de alunos para os anos letivos de 2019 a 2021 do Colégio Universitário Geraldo Reis (Coluni-UFF), que também oferece da Educação Infantil ao Ensino Médio - apenas na modalidade regular -, não há nenhuma menção quanto à reserva de vagas para grupos historicamente excluídos. O ingresso para essa instituição se deu por sorteio público em todos os editais analisados, para todos os segmentos escolares (COLUNI-UFF, 2018, 2019, 2021).

Os Colégios de Aplicação estão subordinados às universidades e suas legislações, sejam estaduais, sejam federais. Essa é uma possível justificativa para os diferentes modos de instrumentalização da política de cotas. Os três casos anteriormente relatados são completamente diferentes quanto ao fator temporal/histórico: o CAp-Uerj, que segue o pioneirismo da própria Uerj na instrumentalização de cotas, aplicando-as a todos os segmentos desde 2014; o CAp-UFRJ, que, nos últimos anos, ampliou gradualmente a aplicação do sistema de cotas a todos os seus segmentos; e o Coluni-UFF, que não aplica as políticas de cotas de nenhuma maneira. Essas instituições não oferecem o Ensino Médio-Técnico disposto na Lei $n$. 12.711/2012 e, portanto, nenhuma delas tem obrigatoriedade legal de realizar a reserva de vagas. Apesar da constatação diária das desigualdades sociais e raciais da nossa sociedade, a reserva de vagas ainda depende da iniciativa de cada instituição de trazer para seus bancos escolares um grupo de alunos diferente do tipo hegemônico branco.

É importante trazer à baila o que cada Colégio de Aplicação considera como primeiro recorte para a reserva de vagas. Para o CAp-Uerj, o primeiro critério é o socioeconômico e, dentro dele, encontram-se subcotas por critério racial - aplicadas a todos os segmentos - e subcotas por origem escolar - aplicadas somente para o Ensino Fundamental II e para o Ensino Médio. Já o CAp-UFRJ aplica os critérios racial e socioeconômico isolada e conjuntamente para a Educação Infantil e para o Ensino Fundamental I. Para o Ensino Fundamental II e para o Ensino Médio, o primeiro recorte é o de origem escolar. 
Os casos apresentados aqui nos mostram que, havendo o comprometimento da instituição com a modificação do perfil hegemônico da comunidade escolar, é possível iniciar o processo de construção de uma outra escola, por meio do sistema de cotas. Ladson-Billings afirma que "nós não podemos esperar que aqueles que controlam a sociedade façam movimentos benevolentes ou altruísticos para justiça racial” (2013, p. 38, tradução nossa). Isso significa que não podemos esperar que se efetive na legislação uma política de cotas raciais para todos os segmentos da educação básica. O tensionamento do poder público precisa acontecer em via dupla, de dentro da instituição para fora (forças organizadas dentro das instituições pressionando as instâncias decisórias), e de fora para dentro (a instituição aprendendo com os movimentos sociais negros externos à escola).

\section{Aspectos Metodológicos da Pesquisa}

Seguindo as premissas da pesquisa qualitativa interpretativista (OLIVEIRA, 2015), recorremos ao estudo de caso para investigar como o CPII considera as políticas de cotas raciais ao operacionalizar os processos seletivos de alunos para os diferentes segmentos da educação básica oferecidos pela instituição.

Segundo Martins (2008), o estudo de caso é uma estratégia de pesquisa sustentada por uma plataforma teórica, que reúne o maior número possível de informações, em função das questões e proposições orientadoras da pesquisa, além de ser baseado em uma investigação empírica, que pesquisa fenômenos dentro do seu contexto real. Este artigo revela-se, portanto, como um estudo de caso porque busca descrever, compreender, discutir e analisar a complexidade de um caso concreto, bem como por focar em fenômenos complexos e contemporâneos.

De acordo com Geertz, “o locus de estudo não é o objeto de estudo” (2008, p. 16). É preciso, portanto, evidenciar que nossa proposta não é estudar a instituição em si, mas investigar as políticas institucionais no tocante ao marcador racial nos processos seletivos de alunos que ocorrem no CPII.

Ademais, vale frisar que uma das autoras deste artigo atua como docente no CPII e, como professorapesquisadora, faz parte do campo de observação. Nesse sentido, Melucci afirma:

O pesquisador aparece inevitavelmente situado, movido por interesses e papéis institucionais que não podem ser esquecidos nem vistos como impedimento ao conhecimento, mas sim considerados como elementos constitutivos do campo que torna possível a reflexão e a pesquisa e que legitimam o produto como saber social (2005, p. 11).

Para que esta pesquisa se materializasse, analisamos, além da legislação vigente, os documentos institucionais que norteiam a operacionalização da política de cotas nos diferentes níveis da educação básica no CPII. Desse modo, tomamos para análise os editais de admissão de estudantes do período compreendido entre 2012 e 2020 - referentes à admissão para os anos letivos subsequentes - para os segmentos da educação básica, a saber: Educação Infantil, Ensino Fundamental I, Ensino Fundamental II e Ensino Médio. O recorte iniciado em 2012 se justifica por ser o ano de promulgação e vigência dos efeitos da Lei n. 12.711. O último edital publicado até a finalização deste artigo é o que se destina ao ingresso de estudantes para o ano letivo de 2021.

Os editais analisados neste estudo relacionam-se com os processos seletivos do CPII, de acordo com os diferentes segmentos da educação básica: 1) ingresso na Educação Infantil, sendo considerados os certames referentes ao acesso de alunos com 4 anos de idade; 2) ingresso nos anos iniciais do Ensino Fundamental, sendo considerados os certames para acesso ao $1^{\circ}$ ano; 3 ) ingresso nos anos finais do Ensino Fundamental, 
sendo considerados os certames para acesso ao $6^{\circ}$ ano; 4) ingresso no Ensino Médio, sendo considerados os certames para acesso ao $1^{\circ}$ ano, na modalidade regular diurna.

A Tabela 1 sumariza os editais que foram efetivamente considerados ao longo das análises e reflexões propostas neste artigo. Deve-se ponderar que tal tabela compreende formas distintas de ingresso. Os editais para a Educação Infantil e para os anos iniciais do Ensino Fundamental apresentam o sorteio público como forma de seleção. Nos editais para acesso aos anos finais do Ensino Fundamental e ao Ensino Médio, publicados de 2012 a 2019, encontramos as orientações para aplicação de provas de seleção e classificação. Em 2020, não houve publicação de editais devido ao atraso do calendário escolar causado pela pandemia da Covid-19. Por meio da Portaria n. 1.801, de 26 de outubro de 2020, foi deliberado que, para o ano letivo de 2021, todos os segmentos teriam o sorteio público como meio de admissão de alunos, em virtude do cenário pandêmico, inclusive para o $6^{\circ}$ ano do Ensino Fundamental e a $1^{\text {a }}$ série do Ensino Médio regular e integrado (COLÉGIO PEDRO II, 2020b).

Tabela 1. Editais analisados na pesquisa por segmento específico. (2012 a 2021)

\begin{tabular}{cccc}
\hline Educação Infantil & $\begin{array}{c}\text { Anos iniciais do } \\
\text { Ensino Fundamental }\end{array}$ & $\begin{array}{c}\text { Anos finais do } \\
\text { Ensino Fundamental }\end{array}$ & Ensino Médio \\
\hline Edital 3/2012 & Edital 9/2012 & Edital 11/2012 & Edital 1/2012 \\
\hline Edital 1/2013 & Edital 7/2013 & Edital 9/2013 & Edital 10/2013 \\
\hline Edital 10/2014 & Edital 11/2014 & Edital 13/2014 & Edital 14/2014 \\
\hline Edital 33/2015 & Edital 34/2015 & Edital 36/2015 & Edital 37/2015 \\
\hline Edital 28/2016 & Edital 29/2016 & Edital 31/2016 & Edital 32/2016 \\
\hline Edital 43/2017 & Edital 44/2017 & Edital 49/2017 & Edital 50/2017 \\
\hline Edital 26/2018 & Edital 27/2018 & Edital 32/2018 & Edital 33/2018 \\
\hline Edital 43/2019 & Edital 44/2019 & Edital 28/2019 & Edital 29/2019 \\
\hline Edital 13/2021 & Edital 14/2021 & Edital 16/2021* & Edital 20/2021* \\
\hline
\end{tabular}

${ }^{*}$ Caracterizando uma excepcionalidade nos padrões dos certames do CPII, no ano de 2021, a seleção discente para os anos finais do Ensino Fundamental e para o Ensino Médio se deu por sorteio público. Fonte: Elaboração própria (2021)

Para termos uma visão geral do alunado do CPII, apresentamos o perfil discente geral da instituição, no qual se somam todos os campi, quanto à cor/raça e quanto à renda familiar no período de 2014 a 2019. Esse recorte de tempo justifica-se por a disponibilidade de dados no site do colégio ocorrer somente a partir de 2014. O perfil discente quanto a cor/raça e renda familiar do ano de 2020 não foi divulgado pela instituição até a finalização deste artigo e, por isso, não compõe o estudo.

Considerando que as cotas por origem escolar estão explícitas nos editais do CPII desde 2004 para os Ensinos Fundamental II e Médio e que as subcotas por critério racial e socioeconômico estão em vigor desde 2012 para o Ensino Médio, é esperado que o perfil dos alunos da instituição tenha mudado nesse período, ao menos nesses segmentos específicos da educação básica. Para essa análise, apresentamos o perfil discente dos diferentes campi II $^{3}$ - que atendem aos Ensinos Fundamental II e Médio - em 2019 para analisar o impacto das políticas de cotas nesses segmentos específicos.

Para embasar a discussão sobre o sorteio público ser ou não orientado pela democratização, apresentamos o perfil discente do Centro de Referência em Educação Infantil Realengo e dos diferentes campi I - que atendem exclusivamente ao primeiro segmento do Ensino Fundamental -, pois tanto o Ensino Fundamental I quanto a Educação Infantil utilizam o sorteio público como forma de seleção desde a inauguração dessas etapas da educação na instituição, em 1984 e 2014, respectivamente. 
É preciso evidenciar que, ao trazermos os dados referentes ao perfil racial do corpo discente do CPII, não há uma suposição implícita de que todos os alunos negros da instituição tenham ingressado por cotas. Essa seria mais uma face do racismo estrutural se manifestando academicamente. Os perfis discentes - geral e por campus - integram esta pesquisa para evidenciar a necessidade de discussão da política de cotas raciais no CPII.

\section{Como as Vagas Discentes São Distribuídas no CPII?}

O CPII, desde 2012 legalmente equiparado aos IF, possuía, em 2019, um total de 13 mil alunos, divididos em catorze campi no estado do Rio de Janeiro (COLÉGIO PEDRO II, 2021a).

Até o ano de 2020, as provas classificatórias de português, matemática e redação eram o método de seleção de alunos do $6^{\circ}$ ano em diante. A seleção de estudantes para os cursos do Ensino Médio integrado conta também com a aplicação de provas de conhecimentos específicos. Já o ingresso nos cursos do Programa de Educação de Jovens e Adultos (PROEJA) é feito por sorteio público de vagas, para alunos com 18 anos ou mais (COLÉGIO PEDRO II, 2021b).

Destacamos que os alunos que entram na Educação Infantil e no Ensino Fundamental I por sorteio permanecem na instituição, sem necessidade de passar por provas de seleção e classificação para avançarem aos demais segmentos da educação básica.

Em 2004, a escola adotou a política de reserva de 50\% das vagas para candidatos egressos de escola pública nos concursos de admissão para o segundo segmento do Ensino Fundamental e para o Ensino Médio. A diretriz foi adotada com base no Projeto de Lei n. 3.627/2004 do governo federal que, com o intuito de alterar o perfil das universidades federais, instituía a reserva de vagas para estudantes que tivessem cursado integralmente o Ensino Médio em escolas públicas. Mesmo não oferecendo educação em nível superior naquele momento, o CPII adotou em seus concursos de admissão essa política de cotas sociais - metade das vagas para o $6^{\circ}$ ano do Ensino Fundamental e para o $1^{\circ}$ ano do Ensino Médio foi destinada a candidatos egressos da rede pública de ensino.

Entretanto, mesmo objetivando a democratização da educação, a política de cotas sociais se revela insuficiente diante do cenário histórico-social brasileiro. Segundo Dargains, "sua adoção [cotas sociais], muitas vezes, pode não se mostrar tão eficiente no combate à desigualdade racial, já que esse tipo de desigualdade se constituiu como um cancro em nossa história, se incrustando no interior da própria desigualdade social" (2015, p. 14).

Com a Lei n. 12.711/2012, o CPII, que oferece curso técnico integrado ao Ensino Médio, passou a adotar, a partir dos editais publicados em 2012 - para ingresso no ano letivo de 2013 -, as subcotas por critérios socioeconômicos e raciais para o acesso ao Ensino Médio em todas as modalidades - regular, técnico e PROEJA. Assim, o colégio passou a considerar os critérios raciais e socioeconômicos como subcotas dentro da reserva de vagas para alunos egressos de escola pública, já em vigor desde 2004 na instituição.

Portanto, desde 2012, a distribuição das vagas nos concursos de seleção e classificação de novos alunos, tanto para o $6^{\circ}$ ano do Ensino Fundamental quanto para o $1^{\circ}$ ano do Ensino Médio, é feita a partir de dois grupos: 1) escola pública e 2) ampla concorrência (escola particular, mesmo com bolsa de estudo). Todavia, para o Ensino Médio, o grupo 1 subdivide-se considerando critérios de renda e raça: a) escola pública + critério socioeconômico + Pretos, Pardos e Indígenas (PPI); b) escola pública + critério socioeconômico; c) escola pública + PPI; e d) escola pública.

Tomando como exemplo a distribuição de vagas para o campus Realengo II (Edital n. 1/2012), no primeiro ano de vigência da Lei n. 12.711/2012, das 120 vagas oferecidas para o Ensino Médio regular diurno, 32 foram destinadas a pretos, pardos e indígenas. No certame de seleção e classificação de candidatos para 
o ano letivo de 2020 para esse mesmo campus e ano de escolaridade (Edital n. 29/2019), do total de oitenta vagas, 24 foram reservadas a candidatos autodeclarados pretos, pardos e indígenas.

Esses dados mostram que a escola cumpre, stricto sensu, a legislação calcada na interpretação literal do texto da Lei n. 12.711/2012. Contudo, evocamos a reflexão sobre as possibilidades de ampliação de políticas institucionais que viabilizem o acesso de estudantes sob os critérios racial e socioeconômico nos concursos de seleção para todos os segmentos da educação básica no CPII. A despeito de a legislação apresentar fragilidades, por não regulamentar a reserva de vagas para além dos Ensino Superior e MédioTécnico, o CPII, por possuir autonomia, poderia aplicar o critério racial também para Educação Infantil e Ensino Fundamental.

As formas de ingresso no CPII historicamente se configuraram como um mecanismo de distinção, de garantia da qualidade e da reputação da escola. O alto grau de seletividade faz parte de um conjunto de estratégias organizadas para diferenciação da instituição frente às outras escolas de ensino básico e da valorização de seus diplomas no mercado de trocas simbólicas (BASTOS, 2017, p. 146).

É possível que haja - na comunidade escolar do CPII e na sociedade como um todo - um entendimento de que a política de cotas raciais, da maneira como tem sido atualmente operacionalizada, é suficiente para modificar o corpo discente da instituição. A seguir, apresentaremos os dados referentes aos perfis racial e socioeconômico familiar dos alunos que ingressaram no CPII nos últimos anos, englobando todos os segmentos da educação básica. Esse perfil geral demonstra a necessidade urgente de uma instrumentalização mais ampla da política de cotas, para trazer ao contexto do CPII outro perfil de aluno.

\section{O Perfil Discente do CPII}

O CPII apura cor/raça dos alunos de maneira autodeclaratória, no momento da matrícula, realizada pelos responsáveis dos alunos menores de idade. Os dados da Tabela 2 são resultado de informações levantadas pela Seção de Planejamento e Pesquisa Institucional (DGC/PRODI) sobre o perfil discente dos anos de 2014 a 2019.

Com base nos dados apresentados na Tabela 2, podemos chegar a constatações importantes sobre o perfil do alunado da instituição. O quantitativo de alunos brancos no colégio é expressivamente superior ao de alunos de outras cores/raças e cresce a cada ano, com exceção de 2019. Embora o percentual de alunos negros também tenha aumentado a cada ano, podemos inferir, com base na tabela, que o CPII ainda está em processo para alcançar o acesso satisfatório de alunos pretos e pardos. Tendo em vista que a população que se autodeclara negra no Brasil, de acordo os dados divulgados pela Pesquisa Nacional por Amostra de Domicílios (PNAD-C) realizada em 2018 (IBGE, 2019), é de 56,2\%, a soma dos percentuais de alunos pardos e pretos deveria se aproximar disso.

Destacamos também o quantitativo baixíssimo de alunos pretos na instituição. Embora o IBGE utilize a categoria negros englobando pardos e pretos, é preciso refletir sobre o racismo peculiar vivido no Brasil, relacionado ao fenótipo. A ideologia do branqueamento (DOMINGUES, 2003; MOURA, 2014; MUNANGA, 2001) constituiu uma população parda maciça no Brasil, o que justifica o maior número de pardos em comparação com o de pretos no CPII. Contudo, essa fragmentação cromática está subordinada a um código de valores racistas que dificulta ou até impossibilita o acesso de pessoas pretas a espaços de prestígio que viabilizem as mobilidades social, cultural e política, como a escola (MOURA, 2014). Segundo Nogueira (2006), no Brasil, a probabilidade de um indivíduo sofrer racismo está diretamente relacionada à 
intensidade de suas marcas raciais. A miscigenação, portanto, não democratizou a sociedade brasileira, mas criou em cima dessa população miscigenada uma escala de valores discriminatória (MOURA, 2014).

Tabela 2. Perfil discente geral do CPII quanto a cor/raça e renda familiar mensal - 2014 a 2019 (em \%)

\begin{tabular}{ccccccc}
\hline \multirow{2}{*}{ Cor/raça autodeclarada na matrícula } & \multicolumn{7}{c}{ Ano } \\
\cline { 2 - 7 } & $\mathbf{2 0 1 4}$ & $\mathbf{2 0 1 5}$ & $\mathbf{2 0 1 6}$ & $\mathbf{2 0 1 7}$ & $\mathbf{2 0 1 8}$ & $\mathbf{2 0 1 9}$ \\
\hline Branca & 36,38 & 45,39 & 52,13 & 55,55 & 57,29 & 56,33 \\
\hline Parda & 12,42 & 18,49 & 21,41 & 24,19 & 26,61 & 28,16 \\
\hline Preta & 3,35 & 5,31 & 6,17 & 7,03 & 8,32 & 9,28 \\
\hline Amarela & 0,11 & 0,25 & 0,42 & 0,57 & 0,57 & 0,57 \\
\hline Indígena & 0,05 & 0,07 & 0,10 & 0,16 & 0,14 & 0,20 \\
\hline Não declarada & 17,24 & 19,32 & 15,72 & 11,45 & 6,78 & 5,43 \\
\hline Sem informação & 30,45 & 11,17 & 4,06 & 1,05 & 0,28 & 0,03 \\
\hline Renda familiar mensal autodeclarada & & & \multicolumn{2}{c}{ Ano } & & \\
& $\mathbf{2 0 1 4}$ & $\mathbf{2 0 1 5}$ & $\mathbf{2 0 1 6}$ & $\mathbf{2 0 1 7}$ & $\mathbf{2 0 1 8}$ & $\mathbf{2 0 1 9}$ \\
\hline Até 1 salário-mínimo (SM) & 10,08 & 13,26 & 13,16 & 15,04 & 17,41 & 18,32 \\
\hline De 1 a 3 SM & 31,44 & 30,85 & 38,87 & 39,27 & 40,40 & 50,84 \\
\hline Maior que 3 SM & 22,53 & 29,22 & 26,89 & 26,12 & 25,62 & 23,43 \\
\hline Não declarada & 35,93 & 16,66 & 21,08 & 19,57 & 16,56 & 17,98 \\
\hline Valor-referência do SM, no ano (em R\$) & 724,00 & 788,00 & 880,00 & 937,00 & 954,00 & 998,00 \\
\hline
\end{tabular}

Fonte: Elaboração própria com base em Colégio Pedro II (2021c).

Também é possível observar que o quantitativo que não declara ou omite a informação quanto à cor/raça decresce a cada ano. Sobre esse ponto, inferimos que se deve ao avanço do debate racial na escola e na sociedade como um todo, capitaneado pelos diversos movimentos sociais negros.

Sobre a conjuntura da renda familiar mensal autodeclarada, a primeira inferência que levantamos é a de que o percentual de discentes que não declaram a renda familiar não engloba famílias em posição de vulnerabilidade socioeconômica, pois, para ter acesso a benefícios da assistência estudantil - em vigor na instituição desde 2014 -, é preciso informar e comprovar a renda.

Por não sabermos quantos membros compõem cada família, trazemos à baila o estudo de Perrut $\mathrm{e}$ Scalercio (2019), em que investigam os marcadores sociais da diferença, os quais estruturam a realidade social dos discentes cotistas e não cotistas no campus São Cristóvão III do CPII. Os autores destacam que o "acesso a 'cota social' tem a ver com a renda per capita: quanto maior o número de indivíduos que moram na mesma casa que esses alunos, maior a possibilidade deste aluno estar incluído nessa modalidade" (PERRUT; SCALERCIO, 2019, p. 26). Eles explicam também que os "estudantes cotistas diferem dos não cotistas principalmente no que diz respeito ao número de familiares em casa e estrutura das moradias” (PERRUT; SCALERCIO, 2019, p. 35).

Ao cruzarem os indicadores socioprofissionais dos pais com a autodeclaração dos alunos cotistas do campus São Cristóvão III, Perrut e Scalercio afirmam ainda que:

[...] os pais de alunos pardos são aqueles que, proporcionalmente, mais apresentam nível de formação médio completo (50\%), seguidos de brancos (28\%) e negros (22\%). Ao se falar de responsáveis com Ensino Fundamental incompleto, apresenta-se taxa de proporção praticamente igual em todas as raças. Entretanto, quando olhamos os responsáveis com nível superior completo, desponta o número de pais de brancos (65\%) comparado ao de alunos negros e pardos (15\% e 20\%, respectivamente) (2019, p. 29). 
Destacamos que a Tabela 2 apresenta o perfil geral, unindo todos os campi, bem como alunos cotistas e não cotistas de todos os segmentos.

Portanto, de maneira geral, podemos considerar que, mesmo com a adoção de cotas sociais por origem escolar nos concursos de admissão de alunos a partir do $6^{\circ}$ ano de escolaridade e de cotas raciais e socioeconômicas para o Ensino Médio, essas medidas modificaram muito pouco o perfil da instituição.

As cotas raciais, adotadas no Ensino Médio desde 2012, deveriam trazer para a instituição um novo corpo discente, pelo menos nesse segmento específico da educação básica. Entretanto, não é o que se constata ao observarmos o perfil discente dessa etapa em alguns campi. A Tabela 3 traz à baila o perfil discente do ano letivo de 2019 (dado mais recente disponível à época da construção deste artigo), dos campi que atendem do segundo segmento do Ensino Fundamental ao Ensino Médio.

Os números relacionados à cor/raça dos estudantes são divulgados por campi e não por segmento, o que dificulta nossa avaliação quanto à eficácia das cotas raciais, pois alguns campi II atendem, além do Ensino Médio, o segundo segmento do Ensino Fundamental, etapa que não é contemplada, legalmente, com as cotas raciais. Portanto, observaremos com maior atenção os dados dos campi Niterói, Duque de Caxias e São Cristóvão III, que oferecem exclusivamente o Ensino Médio.

Tabela 3. Perfil discente dos anos finais do Ensino Fundamental e do Ensino Médio do CPII em 2019 quanto à cor/raça (em \%)

\begin{tabular}{|c|c|c|c|c|c|c|c|c|c|}
\hline \multirow[b]{2}{*}{ Cor/raça } & \multicolumn{9}{|c|}{ Campi } \\
\hline & Centro & $\begin{array}{c}\text { Duque } \\
\text { de Caxias }\end{array}$ & $\begin{array}{c}\text { Engenho } \\
\text { Novo II }\end{array}$ & $\begin{array}{c}\text { Humaitá } \\
\text { II }\end{array}$ & Niterói & $\begin{array}{c}\text { Realengo } \\
\text { II }\end{array}$ & $\begin{array}{c}\text { São Cristóvão } \\
\text { II }\end{array}$ & $\begin{array}{c}\text { São Cristóvão } \\
\text { III }\end{array}$ & $\begin{array}{c}\text { Tijuca } \\
\text { II }\end{array}$ \\
\hline Branca & 60,52 & 34,62 & 61,39 & 69,35 & 50,54 & 48,24 & 57,71 & 52,54 & 63,02 \\
\hline Parda & 22,41 & 44,14 & 26,36 & 18,81 & 35,51 & 32,82 & 28,32 & 28,44 & 20,04 \\
\hline Preta & 8,08 & 16,30 & 8,59 & 5,80 & 10,33 & 9,41 & 11,35 & 9,23 & 7,50 \\
\hline Amarela & 1,02 & 0,92 & 0,51 & 0,50 & 1,27 & 0,37 & 0,10 & 0,46 & 0,44 \\
\hline Indígena & 0,57 & 0,37 & 0,17 & 0,08 & 0,00 & 0,12 & 0,19 & 0,28 & 0,26 \\
\hline Não declarada & 7,39 & 3,66 & 2,98 & 5,47 & 2,36 & 9,04 & 2,13 & 8,86 & 8,74 \\
\hline
\end{tabular}

Fonte: Elaboração própria com base em Colégio Pedro II (2021c).

Apenas no campus Duque de Caxias o número de alunos negros $(60,44 \%)$ é maior que o de alunos brancos (34,62\%). No campus Niterói, o quantitativo de alunos negros $(45,34 \%)$ se aproxima do quantitativo de alunos brancos (50,54\%). Somente nesses dois campi os índices de alunos negros ficam dentro da margem do índice nacional da população negra. Em São Cristóvão III, são 37,67\% de alunos negros e 52,54\% brancos. O campus Realengo II, que oferece turmas do $6^{\circ}$ ano do Ensino Fundamental ao Ensino Médio, aproxima o total de negros (42,23\%) e brancos (48,24\%). O campus Humaitá II, localizado na zona sul da cidade do Rio de Janeiro, é o que apresenta maior diferença entre estudantes negros $(24,61 \%)$ e brancos (69,35\%), seguido do campus Tijuca II, que apresenta percentual de 27,54\% para negros e 63,03\% para brancos. Esses dois campi destacam-se também por apresentarem os menores índices de alunos pretos: 5,80\% no Humaitá II e 7,50\% no Tijuca II.

Bastos (2017), em sua pesquisa sobre o início da política de cotas raciais no CPII, aponta a hipótese da ocorrência de um processo de autoeliminação dos jovens pelo conjunto de fatores relacionados à alta reputação da escola. A pesquisadora apresenta dados quantitativos que indicam número reduzido de inscritos oriundos da rede pública de ensino: “a população que enfrenta maior desigualdade é também a que menos se inscreve [...] o que se percebe é que a possibilidade de se tornar aluno ou aluna do CPII vincula-se mais às estratégias escolares de famílias de determinados grupos sociais” (BASTOS, 2017, p. 144). 
Ainda de acordo com Bastos (2017), a classe média, por dispor de recursos adicionais e compreender a educação dentro de uma lógica de ascensão social, lança mão de investimentos educacionais que se configuram como mecanismos de diferenciação, tais como professores particulares e cursos preparatórios, na corrida por uma vaga no processo meritocrático de seleção de alunos empreendido pelo colégio a partir do segundo segmento do Ensino Fundamental.

Se, na disputa por meio de provas classificatórias, a classe média se sai melhor por dispor de recursos diversos, o processo seletivo feito por sorteio público, para a Educação Infantil e Ensino Fundamental I, deveria trazer maiores diversidades socioeconômica e racial para o processo de seleção e, consequentemente, para a constituição do corpo discente. Entretanto, não é o que os números evidenciam - conforme observa-se na Tabela 4.

Tabela 4. Perfil discente da Educação Infantil e dos anos iniciais do Ensino Fundamental do CPII em 2019 quanto à cor/raça (em \%)

\begin{tabular}{ccccccc}
\hline \multirow{2}{*}{ Cor/raça } & \multicolumn{7}{c}{ Campi } \\
\cline { 2 - 7 } & $\begin{array}{c}\text { Centro de Referência em } \\
\text { Educação Infantil Realengo }\end{array}$ & $\begin{array}{c}\text { Engenho } \\
\text { Novo I }\end{array}$ & $\begin{array}{c}\text { Humaitá } \\
\text { I }\end{array}$ & $\begin{array}{c}\text { Realengo } \\
\text { I }\end{array}$ & $\begin{array}{c}\text { São Cristóvão } \\
\text { I }\end{array}$ & $\begin{array}{c}\text { Tijuca } \\
\text { I }\end{array}$ \\
\hline Branca & 50,30 & 54,31 & 68,06 & 52,07 & 49,47 & 61,93 \\
\hline Parda & 33,73 & 32,46 & 20,88 & 37,14 & 34,51 & 22,02 \\
\hline Preta & 12,43 & 10,42 & 6,05 & 8,30 & 10,36 & 11,93 \\
\hline Amarela & 0,00 & 0,80 & 0,21 & 0,41 & 0,96 & 0,82 \\
\hline Indígena & 0,00 & 0,20 & 0,00 & 0,00 & 0,11 & 0,62 \\
\hline Não declarada & 3,55 & 1,80 & 4,80 & 2,07 & 4,59 & 2,67 \\
\hline
\end{tabular}

Fonte: Elaboração própria com base em Colégio Pedro II (2021c).

O perfil discente quanto à cor/raça nas etapas iniciais da educação básica é semelhante ao das etapas finais. Os campi instalados nos bairros do Humaitá e da Tijuca apresentam maior disparidade no percentual entre brancos e negros. Os campi localizados nos bairros de Engenho Novo, Realengo e São Cristóvão apresentam índices mais equitativos.

Segundo Machado et al., "o sorteio público apenas parece orientado por isonomia, mas seus resultados não geram isonomia de fato", dado o caráter aleatório do sorteio, que "relega ao acaso, à sorte, a concretização do direito à educação de grupos excluídos dela" (2020, p. 913).

Bastos (2017) aponta também o capital informacional como fator que influencia a escolha do colégio e posterior inscrição. Informações acerca do período da seleção, a adequada compreensão dos termos do edital e da própria estrutura das cotas, do funcionamento da escola e de seu caráter público são colocadas pela autora como possíveis dificultadores. A comunicação do processo atualmente é realizada por intermédio da página oficial da escola na Internet e via redes sociais.

Por reconhecerem a desigualdade no ingresso, alguns servidores do CPII e responsáveis de alunos começaram, em 2017, a divulgar em favelas e periferias do Rio de Janeiro informações sobre editais, taxas de inscrição, períodos de isenção etc. A ação, que começou por iniciativa isolada desses servidores, os quais entregavam panfletos e conversavam com pessoas nas comunidades, foi sendo ampliada com o passar dos anos e passou a contar com o apoio do GT de negros e negras do Sindicado dos Servidores do Colégio Pedro II (Sindscope) e do Núcleo de Estudos Afro-brasileiros e Indígenas (NEABI) do CPII. Constituiu-se, assim, um grupo autônomo denominado CPII Popular, que, além de divulgar informações pertinentes ao ingresso de discentes no Colégio, ainda busca doações junto à sociedade civil para pagamento das inscrições, visto que o período de isenção é extremamente curto. 
Portanto, percebe-se que, a despeito das lacunas na legislação vigente e da instrumentalização da política de cotas raciais apenas no sentido estrito da lei no CPII, é por intermédio de iniciativas solidárias e coletivas da comunidade escolar que se estabelece um conjunto de medidas que, de alguma forma, objetivam enegrecer o corpo discente do CPII, de modo a torná-lo um espaço escolar mais inclusivo e diverso, em termos raciais.

\section{Considerações Finais}

Apesar da vigência da Lei n. 12.711/2012 há quase uma década, a discussão em torno da operacionalização do sistema de cotas está longe de terminar. As lacunas verificadas na legislação apontam para a necessidade de tomarmos um caminho ainda mais intenso de estudos e debates para que os direitos da população negra se materializem. Só assim será possível provocar o Legislativo, o Judiciário e as instâncias gestoras das instituições a uma ampliação efetiva da política de cotas raciais.

Acreditamos que a existência de escolas públicas de excelência perfaça um desejo comum de todos que buscam uma sociedade menos desigual. Entretanto, enquanto não realizamos esse desejo utópico, é preciso buscar modos de melhorar as escolas públicas que temos e abrir as portas daquelas que são consideradas de "prestígio" para a população em geral, não apenas para um seleto grupo hegemônico.

Atualmente, a questão racial é contemplada como subcota nas políticas institucionais de Ação Afirmativa do CPII apenas nos processos seletivos de alunos para o Ensino Médio. Os demais segmentos da educação básica oferecidos pelo colégio - Educação Infantil e Ensino Fundamental - não utilizam as subcotas por critério racial.

Ao analisarmos o perfil discente do CPII, constatamos que, mesmo com o aumento do número de estudantes pretos e pardos, não houve acesso equitativo em todos os campi. Embora pesquisas evidenciem que há uma concentração intensa de pessoas brancas na zona sul do Rio de Janeiro (CLARKE, 2015), o fato de o campus Humaitá, por exemplo, ter um alunado composto por quase $70 \%$ de brancos nos faz refletir sobre a constituição desse campus, que tem comunidades como a favela Santa Marta a poucos metros. Constatamos também que o sorteio público, que se apresenta como modalidade democrática de acesso, não é suficiente para enegrecer o corpo discente de uma escola centenária e de passado elitista como o CPII. Embora dentro da legalidade, é preciso projetar soluções para a ampliação da política de cotas raciais para todos os segmentos da educação básica, ampliando o debate dentro e fora do CPII, tomando como exemplo instituições como o CAp-Uerj, o CAp-UFRJ, entre outras.

\section{Contribuições dos Autores}

Problematização e conceituação: Coutinho GS, Arruda DO e Oliveira T; Metodologia: Coutinho GS, Arruda DO e Oliveira T; Análise: Coutinho GS, Arruda DO e Oliveira T; Redação: Coutinho GS, Arruda DO e Oliveira T.

\section{Notas}

1. O CAp-Uerj utiliza a nomenclatura "negros, pardos e indígenas" no edital para o ano letivo de 2021.

2. A Resolução n. 13/2019 altera o Estatuto da UFRJ em conformidade com a integração da Escola de Educação Infantil ao Colégio de Aplicação (DOU de 21 jun. 2019). 
3. Os campi São Cristóvão constituem uma exceção ao padrão do CPII pois, graças ao grande número de alunos, são divididos em campus II e III, para Ensino Fundamental II e Ensino Médio, respectivamente.

\section{Referências}

BASTOS, P. Lei de Cotas no Ensino Médio: investigando o acesso de jovens negros e negras ao Colégio Pedro II, 2017. Tese (Doutorado em Política Social) - Escola de Serviço Social. Universidade Federal Fluminense, Niterói, 2017.

BRASIL. Constituição da República Federativa do Brasil. Brasília, DF: Centro Gráfico, 1988.

BRASIL. Lei n. 10.639, de 9 de janeiro de 2003. Altera a Lei n. 9.394, de 20 de dezembro de 1996, para incluir no currículo oficial da Rede de Ensino a obrigatoriedade da temática "História e Cultura Afro-Brasileira". Diário Oficial [da] República Federativa do Brasil, Brasília, DF, 10 jan. 2003.

BRASIL. Lei n. 12.288, de 20 de julho de 2010. Institui o Estatuto da Igualdade Racial. Diário Oficial [da] República Federativa do Brasil, Brasília, DF, 21 jul. 2010.

BRASIL. Lei n. 12.711, de 29 de agosto de 2012. Dispõe sobre o ingresso nas universidades federais e nas instituições federais de ensino técnico de nível médio e dá outras providências. Diário Oficial [da] República Federativa do Brasil, Brasília, DF, 30 ago. 2012a.

BRASIL. Lei n. 12.677, de 25 de junho de 2012. Dispõe sobre a criação de cargos efetivos, cargos de direção e funções gratificadas no âmbito do Ministério da Educação, destinados às instituições federais de ensino e dá outras providências. Diário Oficial [da] República Federativa do Brasil, Brasília, DF, 26 jun. 2012 b.

CAP-UERJ [COLÉGIO DE APLICAÇÃO DA UNIVERSIDADE DO ESTADO DO RIO DE JANEIRO]. Manual do Candidato - 1o ano do Ensino Fundamental. Edital 2021 - Processo Seletivo Instituto de Aplicação Fernando Rodrigues da Silveira. Rio de Janeiro, CAp-Uerj, 2021a. Disponível em: https://www. vestibular.uerj.br/. Acesso em: 5 jun. 2021.

CAP-UERJ [COLÉGIO DE APLICAÇÃO DA UNIVERSIDADE DO ESTADO DO RIO DE JANEIRO]. Manual do Candidato - $6^{\circ}$ ano do Ensino Fundamental e $1^{\circ}$ ano do Ensino Médio. Edital 2021 - Processo Seletivo Instituto de Aplicação Fernando Rodrigues da Silveira. Rio de Janeiro: CAp-Uerj, 2021b. Disponível em: https://www.vestibular.uerj.br/. Acesso em: 5 jun. 2021.

CAP-UFRJ [COLÉGIO DE APLICAÇÃO DA UNIVERSIDADE FEDERAL DO RIO DE JANEIRO]. Edital n. 642, de 6 de julho de 2018. Admissão de alunos ao CAp UFRJ 2019. Rio de Janeiro: CAp-UFRJ, 2018. Disponível em: https://www.cap.ufrj.br/. Acesso em: 5 jun. 2021.

CAP-UFRJ [COLÉGIO DE APLICAÇÃO DA UNIVERSIDADE FEDERAL DO RIO DE JANEIRO]. Edital n. 378, de 26 de junho de 2019. Admissão de alunos ao CAp UFRJ 2020. Rio de Janeiro: CAp-UFRJ, 2019. Disponível em: https://www.cap.ufrj.br/. Acesso em: 5 jun. 2021.

CAP-UFRJ [COLÉGIO DE APLICAÇÃO DA UNIVERSIDADE FEDERAL DO RIO DE JANEIRO]. Edital n. 475, de 26 de novembro de 2020. Admissão de alunos ao CAp-UFRJ 2021. Rio de Janeiro: CAp-UFRJ, 2020. Disponível em: https://www.cap.ufrj.br/. Acesso em: 5 jun. 2021. 
CAVALIERE, A. M. O Colégio Pedro II encontra o século XXI. Revista Contemporânea de Educação, Rio de Janeiro, v. 3, n. 6, p. 187-196, 2008. https://doi.org/10.20500/rce.v3i6.1549

CLARKE, F. Mapas mostram a segregação racial no Rio de Janeiro. Rio de Janeiro: Rio On Watch, 2015. Disponível em: https://rioonwatch.org.br/?p=17005. Acesso em: 20 jul. 2021.

COLÉGIO PEDRO II. CPII apresenta desempenho positivo no IDEB 2019. Rio de Janeiro: Colégio Pedro II, 2020a. Disponível em: https://www.cp2.g12.br/ultimas_publicacoes/225-noticias/10397-cpii-apresentadesempenho-positivo-no-ideb-2019.html. Acesso em: 30 abr. 2021.

COLÉGIO PEDRO II. Portaria n. 1.801, de 26 de outubro de 2020. Rio de Janeiro: Colégio Pedro II/PROEN, $2020 \mathrm{~b}$. COLÉGIO PEDRO II. Memória histórica do CP II. Rio de Janeiro: Colégio Pedro II, 2021a. Disponível em: http://www.cp2.g12.br/images/comunicacao/memoria_historica/index.html. Acesso em: 30 abr. 2021 a.

COLÉGIO PEDRO II. Concursos e seleções - Estude no CPII. Rio de Janeiro: Colégio Pedro II, 2021 b. Disponível em: http://www.cp2.g12.br/component/content/article/81-concursos/10808-concursos-esele\%C3\%A7\%C3\%B5es.html. Acesso em: 10 maio 2021b.

COLÉGIO PEDRO II. CPII em números. Rio de Janeiro: Colégio Pedro II, 2021c. Disponível em: http:// www.cp2.g12.br/proreitoria/prodi/cpii_numeros. Acesso em: 10 jun. 2021.

COLUNI-UFF [COLÉGIO UNIVERSITÁRIO GERALDO REIS]. Edital n. 01/2018. Sorteio para admissão ao Colégio Universitário Geraldo Reis - Educação Infantil, Ensinos Fundamental e Médio - Ingresso no ano letivo de 2019. Niterói: Coluni-UFF, 2018. Disponível em: http://coluni.uff.br/. Acesso em: 5 jun. 2021.

COLUNI-UFF [COLÉGIO UNIVERSITÁRIO GERALDO REIS]. Edital n. 01/2019. Sorteio para admissão ao Colégio Universitário Geraldo Reis - Educação Infantil, Ensinos Fundamental e Médio - Ingresso no ano letivo de 2020. Niterói: Coluni-UFF, 2019. Disponível em: http://coluni.uff.br/. Acesso em: 5 jun. 2021.

COLUNI-UFF [COLÉGIO UNIVERSITÁRIO GERALDO REIS]. Edital n. 01/2021. Sorteio para admissão ao Colégio Universitário Geraldo Reis - Educação Infantil, Ensinos Fundamental e Médio - Ingresso no ano letivo de 2021. Niterói: Coluni-UFF, 2021. Disponível em: http://coluni.uff.br/. Acesso em: 5 jun. 2021.

CUNHA JÚNIOR, C. O Imperial Collegio de Pedro II e o ensino da boa sociedade brasileira. Rio de Janeiro: Apicuri, 2008.

DARGAINS, R. A política invisível: o caso da implantação das cotas raciais no Colégio Pedro II. 2015. Dissertação (Mestrado em Educação) - Faculdade de Educação. Universidade Federal do Rio de Janeiro, Rio de Janeiro, 2015.

DOMINGUES, P. Uma história não contada: negro, racismo e branqueamento no pós-abolição. São Paulo: Senac, 2003.

EEI-UFRJ [ESCOLA DE EDUCAÇÃO INFANTIL DA UNIVERSIDADE FEDERAL DO RIO DE JANEIRO]. Edital n. 895, de 30 de novembro de 2018. Admissão de alunos à Escola de Educação Infantil UFRJ 2019. Rio de Janeiro, EEI-UFRJ, 2018. Disponível em: https://eei.ufrj.br/. Acesso em: 5 jun. 2021.

FERES JÚNIOR, J. et al. Ação Afirmativa: conceito, história e debates. Rio de Janeiro: EdUerj, 2018.

GALVÃO, M. C. S. A jubilação no Colégio Pedro II, que exclusão é essa? 2003. Dissertação (Mestrado em Educação) - Faculdade de Educação. Universidade do Estado do Rio de Janeiro, Rio de Janeiro, 2003. 
GALVÃO, M. C. S. Nós somos a história da educação: identidade institucional e excelência escolar no Colégio Pedro II. 2009. 293 f. Tese (Doutorado em Educação) - Pontifícia Universidade Católica do Rio de Janeiro, Rio de Janeiro, 2009.

GEERTZ, C. A interpretação das culturas. Rio de Janeiro: LTC, 2008.

GOMES, N. L. O movimento negro educador: saberes construídos nas lutas por emancipação. Petrópolis: Vozes, 2017.

IBGE [INSTITUTO BRASILEIRO DE GEOGRAFIA E ESTATÍSTICA]. Conheça o Brasil - População cor ou raça. IBGE Educa. Brasília, DF: IBGE, 2019. Disponível em: https://educa.ibge.gov.br/jovens/conheca-obrasil/populacao/. Acesso em: 5 jun. 2021.

IBGE [INSTITUTO BRASILEIRO DE GEOGRAFIA E ESTATÍSTICA]. Apresentação - PNAD Contínua 2019 - Educação. Relatório de Pesquisa. Brasília, DF: IBGE, 2020. Disponível em: https://agenciadenoticias. ibge.gov.br/. Acesso em: 5 jun. 2021.

LADSON-BILLINGS, G. Critical Race Theory-What It Is Not! In: LYNN, M.; DIXSON, A. D. (eds.). Handbook of Critical Race Theory in Education. New York: Routledge, 2013. p. 54-67.

MACHADO, L. A. S. et al. Trajetória de uma política: cotas étnico-raciais na Escola de Educação Básica da Universidade Federal de Uberlândia. Revista Educação e Políticas em Debate, Uberlândia, v. 9, n. esp., p. 905-920, 2020. https://doi.org/10.14393/REPOD-v9nEspeciala2020-55604

MARTINS, G. Estudo de caso: uma reflexão sobre a aplicabilidade em pesquisas no Brasil. Revista de Contabilidade e Organizações, Ribeirão Preto, v. 2, n. 2, p. 9-18, 2008. https://doi.org/10.11606/rco.v2i2.34702

MELUCCI, A. Por uma sociologia reflexiva - pesquisa qualitativa e cultura. Petrópolis: Vozes, 2005.

MOEHLECKE, S. Ação Afirmativa: história e debates no Brasil. Cadernos de Pesquisa, São Paulo, n. 117, p. 197-217, 2002. https://doi.org/10.1590/S0100-15742002000300011

MOURA, C. Dialética Radical do Brasil Negro. São Paulo: Fundação Mauricio Grabois, 2014.

MUNANGA, K. Políticas de Ação Afirmativa em benefício da população negra no Brasil: um ponto de vista em defesa de cotas. Sociedade e Cultura, Goiânia, v. 4, n. 2, p. 31-43, 2001. https://doi.org/10.5216/sec.v4i2.515

NOGUEIRA, O. Preconceito racial de marca e preconceito racial de origem: sugestão de um quadro de referência para a interpretação do material sobre relações raciais no Brasil. Tempo Social, São Paulo, v. 19, n. 1, p. 287-308, 2006. https://doi.org/10.1590/S0103-20702007000100015

OLIVEIRA, F. L. Triangulação metodológica e abordagem multimétodo na pesquisa sociológica: vantagens e desafios. Ciências Sociais Unisinos, São Leopoldo, v. 51, n. 2, p. 133-143, 2015. https://doi.org/10.4013/ csu.2015.51.2.03

PERRUT, I.; SCALERCIO, V. Estudo sociogeográfico: uma análise da realidade social dos discentes do Colégio Pedro II - unidade de São Cristóvão III. Perspectiva Sociológica, Rio de Janeiro, n. 23, p. 19-38, 2019. https:// doi.org/10.33025/rps.v0i23.2120

SANTOS, S.A. Comissões de heteroidentificação étnico-racial: lócus de constrangimento ou de controle social de uma política pública? O Social em Questão, Rio de Janeiro, n. 50, p. 11-62, 2021. https://doi.org/10.17771/ PUCRio.OSQ.52256 


\section{Sobre os Autores}

Gabriela dos Santos Coutinho é licenciada em Letras (Português-Literaturas) pela Universidade Estácio de Sá (UNESA) e mestranda no Programa de Pós-graduação em Relações Étnico-raciais (PPRER) do Centro Federal de Educação Tecnológica Celso Suckow da Fonseca (Cefet-RJ). É professora efetiva dos Ensinos Básico, Técnico e Tecnológico do Colégio Pedro II e pesquisadora do Núcleo de Estudos Afro-brasileiros e Indígenas (NEABI) dessa mesma instituição. Desenvolve pesquisas sobre letramentos das relações étnicoraciais, políticas públicas educacionais e Ações Afirmativas.

Dyego de Oliveira Arruda é bacharel em Ciências Econômicas pela Universidade Federal de Mato Grosso do Sul (UFMS), mestre em Administração também pela UFMS e doutor em Administração de Organizações pela Universidade de São Paulo (USP). É professor dos Ensinos Básico, Técnico e Tecnológico do Centro Federal de Educação Tecnológica Celso Suckow da Fonseca (Cefet-RJ), credenciado no Programa de Pósgraduação em Relações Étnico-raciais (PPRER) da instituição. Desenvolve pesquisas sobre políticas públicas e Ações Afirmativas.

TAlita de Oliveira é bacharel e licenciada em Letras (Português-Inglês) pela Universidade Federal do Rio de Janeiro (UFRJ), mestre em Linguística Aplicada também pela UFRJ e doutora em Letras (Estudos da Linguagem) pela Pontifícia Universidade Católica de Rio de Janeiro (PUC-Rio). É professora titular dos Ensinos Básico, Técnico e Tecnológico do Centro Federal de Educação Tecnológica Celso Suckow da Fonseca (Cefet-RJ) e docente do Programa de Pós-graduação em Relações Étnico-Raciais (PPRER) e do Programa de Pós-graduação em Filosofia e Ensino (PPFEN) na mesma instituição. Desenvolve pesquisas em estudos narrativos e identitários de orientação sócio-interacional e em letramentos das relações étnico-raciais.

Recebido: 31 jul. 2021

Aceito: 22 out. 2021 